\title{
A study of fetomaternal outcome of hepatic disorders in pregnancy
}

\author{
Mahima Jain*, Himani Thaker \\ Department of Obstetrics and Gynecology, BJ Medical College, Ahmedabad, Gujarat, India
}

Received: 09 January 2019

Accepted: 11 February 2019

\author{
*Correspondence: \\ Dr. Mahima Jain, \\ E-mail: drmahimajain@yahoo.co.in
}

Copyright: $\odot$ the author(s), publisher and licensee Medip Academy. This is an open-access article distributed under the terms of the Creative Commons Attribution Non-Commercial License, which permits unrestricted non-commercial use, distribution, and reproduction in any medium, provided the original work is properly cited.

\begin{abstract}
Background: Liver is a vital organ to maintain physiology of the body and supports every organ of the body. Its proper functioning during pregnancy is essential for a good maternal and fetal outcome. The study analyses the causes and fetomaternal outcome in pregnancies with jaundice and suggests measures to reduce morbidity and mortality.

Methods: This is a one-year prospective study in a tertiary care institute during which 7165 deliveries are conducted. Total 55 cases of Jaundice with pregnancy are identified and studied for clinical, biochemical profile, etiology and maternal and fetal outcome. 8 maternal deaths are reported amongst this study group.

Results: In this study 55 cases of hepatic disorders in pregnancy are studied. The age group reported is 21-29 years. Majority $72 \%$ cases belong to rural areas and $85 \%$ in lower socioeconomic class. $96.3 \%$ patients were in the third trimester of pregnancy. Most common etiology of hepatic disorders in pregnancy is acute viral hepatitis followed by intrahepatic cholestasis of pregnancy and preeclampsia and HELLP syndrome. In acute viral hepatitis $81 \%$ patients were hepatitis E positive. Most common complication are DIC followed by hemorrhagic shock and subsequently AKI and septicemia. $77.7 \%$ babies were born alive and 30.9\% NICU admission due to severe birth asphyxia and prematurity. Of these $16.6 \%$ died in neonatal period. Maternal mortality in $14.5 \%$ patients due to viral hepatits, HELLP and septicemia.

Conclusions: Jaundice in pregnancy is a rare medical disorder and deadly combination affecting maternal and fetal outcome. Earl detection and timely intervention with multidisciplinary approach including obstetrician, neonatologist, intensivist and skilled nursing care can help to reduce maternal mortality and morbidity.
\end{abstract}

Keywords: Fetomaternal outcome, In pregnancy, Jaundice

\section{INTRODUCTION}

Liver is an important organ to maintain the normal physiology of the body and it supports almost every organ of the body and is vital for survival. Especially during pregnancy liver should be functionally normal. In Jaundice in pregnancy of any etiology (hemolytic, viral etc.) liver functions are grossly affected. ${ }^{1}$ Certain physiological changes unique to pregnancyhemodynamic, hormonal and immunological changes may alter the course of both acute and chronic liver diseases. So, liver with abnormal functions can increase the complications in pregnancy and sometimes lead to maternal death. The hepatic functions during pregnancy are affected by increased serum estrogen and progesterone levels. Physical findings such as palmer erythema, spider angioma which may suggest liver disease may be found normally during pregnancy. ${ }^{2}$ However up to $3 \%$ pregnancies are complicated by liver disorders. Certain liver diseases unique to pregnancy like Acute fatty liver of pregnancy, HELLP syndrome occur during the third trimester of pregnancy and are associated with increased morbidity and mortality to both the mother and fetus. These disorders have been suggested to 
represent a spectrum of the same pathologic mechanisms making differentiation among them challenging. Of the patients with AFLP, $50 \%$ have pre-eclampsia and $20 \%$ have severe eclampsia develop HELLP syndrome. Delivery is the most important step in managing these disorders because it can be life saving for both mother and child. . $^{3,4}$

Complications like DIC, thrombocytopenia, renal failure, $\mathrm{PPH}$ and maternal mortality rates are high with the disease. It is responsible for about $60 \%$ of perinatal mortality and $14 \%$ maternal mortality. ${ }^{1}$

The present study analyses the cause and fetomaternal outcome in pregnancies especially in lower and middle socioeconomic classes which are predominantly affected with jaundice. The aims and objectives of the study are to know the incidence of liver disease in our institute, to evaluate the maternal outcome in terms of maternal morbidity and mortality and to evaluate the fetal outcome to be assessed by birth weight neonatal admissions, perinatal morbidity and mortality.

\section{METHODS}

This was a one-year prospective study during which 7165 deliveries were conducted in the institute. Total admission of patients with hepatic diseases were 55 and total deaths due to hepatic diseases were 8 . Patients were identified with altered liver function tests based on history and symptoms. The data was collected, scrutinized for clinical and biochemical profile, etiology, maternal and fetal outcome.

Advice from Physician was taken for better and comprehensive management of patients. Critically ill patients were managed in intensive care units. All patients underwent clinically examination, complete blood count, liver function test, viral hepatitis markers, coagulation profile, abdominal ultrasound. Apart from these additional investigations to know the etiology of the disease were carried out. Patient was monitored as per the standard operating protocols. All pregnant females with liver disease attending indoor and outdoor services of our department and institute were included in this study. Each case was analyzed, computed and tabulated according to standard proforma. Data was analyzed in Microsoft Excel Worksheet.

\section{RESULTS}

As per Table 1 the demographic profile of the patients included majority from 21-29 years which is the peak reproductive age group. Majority of patients belong to rural area since the importance of antenatal registration and visits is not yet established in our country. $85 \%$ patients from lower socioeconomic class are affected which suggests that hepatic disorders from infective origin are related to hygiene and cleanliness which is compromised in this class of patients.
Table 1: The demographic profile of the patients.

\begin{tabular}{|l|l|l|}
\hline Parameter & No. of cases, N=55 & $\%$ \\
\hline$\leq 20$ & 4 & 7.27 \\
\hline $21-29$ & 45 & 81.8 \\
\hline$\geq 30$ & 6 & 10.9 \\
\hline Residence & & \\
\hline Urban & 15 & 27.2 \\
\hline Rural & 40 & 72.7 \\
\hline Socioeconomic class & & \\
\hline Upper & 0 & 0 \\
\hline Middle & 8 & 14.5 \\
\hline Lower & 47 & 85.4 \\
\hline
\end{tabular}

Apart from this there is still dearth of safe drinking water facility in India. In Table 2 In present study $96.3 \%$ patients were from third trimester as many pregnancy specific causes like HELLP syndrome, cholestatic jaundice, acute fatty liver of pregnancy occurs during this gestational age.

Table 2: Association of trimester with jaundice.

\begin{tabular}{|l|l|l|}
\hline Trimester & No. of cases, N=55 & $\%$ \\
\hline First $<12$ weeks & 0 & 0 \\
\hline Second 13-28 weeks & 2 & 36 \\
\hline Third 29-40 weeks & 53 & 96.3 \\
\hline
\end{tabular}

In Table 3 In $23.6 \%$ of the cases coagulation profile was abnormal. Altered coagulation profile further complicates the pregnancy increasing the risk of DIC, AKI and MODS leading to mortality.

Table 3: Analysis of liver function tests and coagulation profile.

\begin{tabular}{|c|c|c|}
\hline Liver function tests & $\begin{array}{l}\text { No. of patients, } \\
N=55\end{array}$ & $\%$ \\
\hline \multicolumn{3}{|c|}{ S. Bilirubin (0.2-1.2 mg/dl) } \\
\hline$<5$ & 25 & 45.4 \\
\hline $5-10$ & 19 & 34.5 \\
\hline $10-15$ & 5 & 9.09 \\
\hline$>15$ & 6 & 10.9 \\
\hline \multicolumn{3}{|l|}{ SGPT (5-40u/l) } \\
\hline$<100$ & 14 & 25.4 \\
\hline $100-1000$ & 31 & 56.3 \\
\hline$>1000$ & 10 & 19.2 \\
\hline \multicolumn{3}{|l|}{ SGOT (5-40u/l) } \\
\hline$<100$ & 12 & 21.8 \\
\hline $100-1000$ & 35 & 63.6 \\
\hline$>1000$ & 8 & 14.5 \\
\hline \multicolumn{3}{|l|}{ Prothrombin time } \\
\hline Normal & 12 & 76.3 \\
\hline Raised & 13 & 23.6 \\
\hline \multicolumn{3}{|l|}{ INR } \\
\hline Normal & 42 & 76.3 \\
\hline Raised & 13 & 23.6 \\
\hline
\end{tabular}


This also stresses the need for component therapy in such patients with altered coagulation profile. This explains the need to manage jaundice in pregnancy in a tertiary care centre. In Table 4 In present study acute viral hepatitis is major etiology in $36.3 \%$ cases followed by choleststic jaundice of pregnancy and HELLP syndrome in $29.09 \%$ and $27.2 \%$.

Table 4: Causes of jaundice in pregnancy.

\begin{tabular}{|l|l|l|}
\hline Causes & No. of cases, N=55 & $\%$ \\
\hline Acute viral hepatitis & 1 & 36.3 \\
\hline A & 3 & \\
\hline B & 0 & 0 \\
\hline E & 17 & 29.09 \\
\hline $\begin{array}{l}\text { Hyperemesis gravidarum } \\
\text { Cholestatic jaundice of } \\
\text { pregnancy }\end{array}$ & 0 & 16 \\
\hline $\begin{array}{l}\text { Pre-eclampsia eclampsia } \\
\text { HELLP }\end{array}$ & 15 & 27.2 \\
\hline $\begin{array}{l}\text { Portal hypertension } \\
\text { Acute fatty liver of } \\
\text { pregnancy }\end{array}$ & 2 & 3.6 \\
\hline
\end{tabular}

Amongst acute viral hepatitis HEV is more common cause which suggest that in developing countries still infective hepatic disorders are found due to unavailability of safe drinking water and proper hygiene.

As shown in the Table 5 most common complications are DIC followed by hemorrhagic shock.

Table 5: Maternal outcome.

\begin{tabular}{|l|l|l|}
\hline Outcome & No. of cases, $\mathbf{N}=55$ & $\%$ \\
\hline Portal hypertension & 3 & 5.4 \\
\hline DIC & 10 & 18.18 \\
\hline Encephalopathy & 3 & 5.4 \\
\hline AKI & 4 & 7.27 \\
\hline Septicemia & 4 & 7.27 \\
\hline Hemorrhagic shock & 5 & 9.09 \\
\hline Death & 8 & 14.5 \\
\hline
\end{tabular}

Jaundice in pregnancy is associated with high morbidity and mortality. This emphasizes the need for availability of critical care and ICU facility to deal with such complications. The causes of maternal death are Acute viral hepatitis in $50 \%$ cases followed by pre-eclampsia, HELLP syndrome.

Hepatitis E Virus infected patients have high mortality since HEV infections are frequent cause of fulminant hepatic failure. In Table 6 , jaundice leads to poor perinatal outcome as birth asphyxia due to low birth weight and IUGR is very common. The reason for NICU admission was prematurity in majority followed by birth asphyxia. Sudden onset fetal distress is common in these patients. Hence, high suspicion with continuous fetal surveillance and delivery soon after lung maturity is helpful.

Table 6: Neonatal outcome.

\begin{tabular}{|l|l|l|}
\hline Outcome & No. of cases, N=55 & $\%$ \\
\hline Live birth & 41 & 77.7 \\
\hline Still birth & 12 & 22.2 \\
\hline Neonatal death & 7 & 16.6 \\
\hline NICU admissions & 13 & 30.9 \\
\hline Severe birth asphyxia & 2 & 4.7 \\
\hline IUGR & 0 & 0 \\
\hline Prematurity & 5 & 1.9 \\
\hline In terms of weight & & \\
\hline$<2 \mathrm{~kg}$ & 26 & 47.2 \\
\hline$>2 \mathrm{~kg}$ & 29 & 52.7 \\
\hline
\end{tabular}

\section{DISCUSSION}

In this study the mean age group is 25.4 years which is the reproductive age group. The mean gestational age in this study is 33.85 weeks which corresponds to third trimester and pregnancy associated hepatic diseases such as acute viral hepatits, cholestatic jaundice of pregnancy and acute fatty liver of pregnancy is common at this gestational age. Most of the tests remain normal in pregnancy except those produced by the placenta like alkaline phosphatase or impacted as a result of hemodilution (hemoglobin, albumin). ${ }^{5}$

Mean fetal weight in this study is about $2.14 \mathrm{~kg}$ which suggest that perinatal outcome is also affected and low birth weight due to preterm delivery is a common perinatal outcome. Many patients needed blood component transfusion on average 2.4 per patient. This indicated the need for readily availability of these components in blood banks. Acute viral hepatitis is the most common cause of hepatic disorders in pregnancy which accounts for $36.3 \%$ in present study and same reported by Jaiswal et al $30.69 \% .^{4}$

The course of events in other viral hepatitis and that of hepatitis $\mathrm{E}$ differs in the fact that hepatitis $\mathrm{E}$ has a fulminant course in pregnancy. ${ }^{6}$ High percentage of Hepatitis E virus positivity suggest that in developing countries still infective hepatic disorders are due to unsafe drinking water and poor hygiene. ${ }^{7}$ Pregnancy appears to be a potential risk factor for viral replication and extremely low immune status of Indian women. The reason for this phenomenon is unclear yet certain reasons have been put forward to prove this.

There is a shift in the $\mathrm{T}$ helper cell balance in pregnancy more towards $\mathrm{TH} 2$ response leading to reduced CD4 and increase in CD8 count and thus causing moderate amount of immunosuppression. This is superadded to the immunosuppressed state of pregnancy. Also, estrogen and progesterone secreted in higher amounts during pregnancy impair the cell mediated immunity by triggering the adaptor protein of $\mathrm{HEV}$ virus (ORF3) 
which facilitates replication of virus and further catastrophe. ${ }^{8}$ The study shows that viral hepatitis still leads the cause of maternal mortality in developing countries like India.Other authors like Parveen $\mathrm{T}$ et al showed a mortality rate of $0.5 \%$ whereas present study reported to be $0.76 \%$ since ours is a tertiary care hospital and referral centre in this region. ${ }^{9}$ Hence complete immunization against viral hepatitis, better sanitation facility, safe drinking water and increased availability of antenatal care for early detection of high-risk pregnancy and well equipped hospital for intensive care will go long way in reducing maternal and perinatal mortality.

\section{CONCLUSION}

Jaundice in pregnancy is a rare medical disorder and also a bad combination which affects maternal and fetal outcome inspite of involving very small amount of population and has a significant impact on outcome of pregnancy. Early detection and timely intervention with the help of multidisciplinary approach including team of obstetrician, neonatologist, intensivist and skilled nursing staff at tertiary care centre to decrease maternal and perinatal morbidity and mortality.

Funding: No funding sources Conflict of interest: None declared

Ethical approval: The study was approved by the Institutional Ethics Committee

\section{REFERENCES}

1. Hepatic, Biliary tract and pancreatic disorders. William's Obstetrics. $22^{\text {nd }}$ ed: 1125-1126.
2. Kamalajayaram V, Devi RA A study of maternal morbidity and mortality in jaundice J Obstet Gynecol India 1988;38:439-41.

3. Fernando A. Shirish N D, Amarnath GB, High Risk pregnancy and delivery, 4th edition, chapter 16: Hypertensive disorders in pregnancy p 221-224.

4. Reyes H Acute fatty liver of pregnancy, Clin Liver Diseases 1999;3:69-81.

5. Singh JM, Mehta GS, A prospective study on acute viral hepatitis in pregnancy, seroprevalence and fetomaternal outcome of 100 cases, J Bio Sci Tech 2011;2(3):279-86.

6. Nayak NC, Pande SK, Patta R, Zuckermann AJ, Gupta DK, Madanagopalan V et al, Aetiology and outcome of acute viral hepatitis in pregnancy $\mathbf{J}$ Gastroenterol Hepatol. 1989;4(4):345-52.

7. Patel BJ, Thaker RV, Shah JM, Bhavna N. Mewada BN, Study of feto-maternal outcome in patients of jaundice in third trimester of pregnancy Int J Reprod Contracept Obstet Gynecol. 2015;4(6):1961-4.

8. Hay JE. Viral hepatitis in pregnancy. Viral hepatitis Reviews 2008;47(3):1067-76.

9. Parveen T, Begum F, Akhtar N. Feto maternal outcome of jaundice in pregnancy at tertiary care hospital. Mymensingh Med J. 2015;24(3):528-36.

Cite this article as: Jain M, Thaker H. A study of fetomaternal outcome of hepatic disorders in pregnancy. Int J Reprod Contracept Obstet Gynecol 2019;8:1182-5. 